\title{
VAMOS SIMPLIFICAR O PROBLEMA DO SER?
}

Jorge Jaime*

\begin{abstract}
SÍNTESE - O Autor sugere a simplificação do problema filosófico sobre o ser. Pretende que os termos sejam bem definidos para uma clareza inicial dos conceitos. Faz um resumo do pensamento de Avicena. Seria o problema ontológico um pseudo-problema? Confronta o ser com o existir. O ser-coisa, o ser-essência evolui para 0 ser-existência, o ser-jogado-no-mundo. 0 homem, sem a sua consciência de valores, nada é. Conclui que o existir é apenas o do homem, ser capaz dos valores. O homem orienta-se para Deus onde habita toda a plena Afirmação.
\end{abstract}

\begin{abstract}
The author suggests a simplification of the philosophical problems about the being. He intends to have a good definition of terms for a initial clarity of the concepts. He makes a summary of Avicena's thought: would the ontological problem be a pseudo one? He confronts "being" with existing", that is, the being thrown into the world. People without a consciousness of their values are reduced to a cipher. He concludes that "existing" is only related to people and their concern with the values. People orientate themselves to God, where all Affirmation lies.
\end{abstract}

Dirijo-me aos ilustres professores de Filosofia que, nas faculdades, ministram aulas sobre a Metafísica. Vamos simplificar o problema do ser? Isto é: vamos concordar que determinadas palavras signifiquem determinado conteúdo factual, verbal, relacional? Se assim não fizermos estaremos dissertando em vão. Cada palavra terá, certamente, um significado, aquilo que "se entende por...". Palavras sem nenhum significado são simples sons e não possuem o poder de comunicação. Absolutamente nada nos transmitem. Da mesma forma os juízos feitos com tais palavras sem conteúdo.

O problema filosófico sobre o ser sempre foi um dos mais difíceis de entendimento. Quando se diz ser o nosso interlocutor entenderá o quê? Que alguma coisa existe? Que coisa"? Todas as coisas? Aristóteles nos falou do "ser enquanto ser". Que será isto? Quando o ser, ou "um" ser deixa de ser?

Logo de saída, nota-se a profunda correlação entre o problema do ser e o problema do conhecimento. Dar uma explicação racional para um será adiantar a explicação do outro. Pode-se entender uma abstração sem o seu respectivo con-

* Membro da Academia Brasileira de Filosofia.

\begin{tabular}{|l|c|c|c|c|c|}
\hline VERTTAS & Porto Alegre & v. 43 & $\mathrm{n}^{0} 2$ & Junho 1998 & p. 387-398 \\
\hline
\end{tabular}


teúdo? Seria uma abstração de quê? Se denomino nadas com nomes, estes representarão, simplesmente, nada, ou seja: nada representarão.

Os filósofos da linguagem procuraram, nos problemas filosóficos, a insensatez de vários argumentos que não encontravam representatividade no mundo real $\mathrm{e}$ que seriam, apenas, simples jogo de palavras. Seriam pseudo-problemas. E, nunca, problemas factuais de natureza gnosiológica.

De início, precisaremos ensinar aos nossos alunos que a palavra ser tem, imediatamente, duas significações: a do verbo ser, que significa existir e se conjuga em todos os seus tempos e modos; a do substantivo ser, que é sinônimo de ente, coisa, animal, vegetal, mineral, espiritual, fictícia, enfim, sempre uma estrutura, um todo perceptível, formado de partes, umas às outras relacionadas, existindo dentro de outras estruturas sempre maiores do que a enfocada.

A maior de todas as estruturas, cuja forma nos é desconhecida, aquilo que se conhece como o Universo, a Realidade, deve sempre vir grafado com letra maiúscula, como o Ser, o todo total, o Um, que é o mundo espacial que habitamos e do qual quase nada sabemos. Assim, o Ser é uma representação, uma denominação da realidade imensa, realista-problemática da qual conhecemos, somente, limitados aspectos. O Ser tem pouco de realista, isto é, de conhecimento, e muito de problemático: de realidade a ser conhecida. Se não fizermos, a cada momento, análises realistas-problemáticas sobre as relações entre as palavras e o seu conteúdo, ao que se referem, estaremos sempre muito distantes do significado dos termos. Raciocinar com palavras que nada significam é fazer, somente, um jogo de sons, destituídos de conteúdo significativo. Sempre que falarmos sobre o ser, ou seres, ou ser (verbo) precisamos explicar ao nosso aluno-interlocutor qual o conteúdo da idéia que pretendemos transmitir-lhe.

Para não assustarmos muito os nossos alunos devemos explicar-lhes, de antemão, antes de enveredarmo-nos em Martin Heidegger, que "o ser do ente" não é um ser que esteja passando mal, que sofra de alguma doença... Mas que este ser tem significado do verbo existir e que, embora venha com um artigo antes dele, não tem significado de substantivo; em outra tradução: o ser do ente significa a existência do ente, ou de um ente, de uma coisa, de uma estrutura.

Não devemos fazer dos problemas filosóficos simples aporias, isto é: caminhos sem saídas, proposições sem conclusões lógicas, dificuldades insuperáveis de um raciocínio ilógico. Não são esses os bons caminhos da Filosofia que, em muitos casos, pretende ser crítica ou o nascedouro das futuras ciências. Ora, sem as definições precisas do eu seja ser, ente, ôntico, e tantos outros termos que se usam no contexto da Filosofia, pouco entenderemos e os nossos alunos, para conseguirem aprovação, fingirão um entendimento que será às proposições cabiveis de transmissão de mente a mente, de cérebro a cérebro. Fora disto estaremos gastando o nosso tempo e o dos alunos igualmente. Será conveniente que, durante nossas aulas de Metafísica, paremos uns momentos para perguntar aos receptores de nossas preleções: o que vocês entendem por estes conceitos? E esperarmos, pacientemente, as suas múltiplas e disparatadas respostas. Se acarearmos dois renomados filósofos e os inquirirmos sobre o que entendem pelos objetos metafísicos veremos que as respostas em nada se igualam. Assim sendo, lançamos no ar o 
problema: como se pode comunicar raciocinios ontológicos usando termos como ser, ente, sem que esses conceitos estejam, em cada cabeça, suficientemente definidos, delineados, esclarecidos? Portanto, professores de Metafisica: primeiramente a perfeita conceituação dos termos; depois, o seguimento racional das premissas e suas lógicas conclusões.

Acredito que o problema do ser seja mais histórico-filosófico do que propriamente racional.

Na Apresentação de Ser e tempo de Martin Heidegger (2. ed. Petrópolis: Vozes, 1988), Emmanuel Carneiro Leão, membro da Academia Brasileira de Filosofia, nos ensina, antecipadamente, como devemos agir para o bom entendimento de suas mensagens: Ser e Tempo é texto de uma língua. Um texto é uma escritura, um sistema de palavras em que algumas sempre de novo recorrem numa cadência regular. Pela regularidade, as palavras parecem desempenhar uma força e por isso mesmo se nos afiguram as palavras-chave de todo o texto. A primeira fase de uma tentativa de leitura consiste em familiarizar-se com as palavras-chave, estabelecendo-lhes a função sintática e a remissão semântica no todo do sistema. Mesmo que, de início, o esforço se reduza à simples consulta de um dicionánio filosófico, para se responder à pergunta - qual a significância, isto é, a função e o significado que exercem no todo do sistema palavras como ser e ente, sentido e presença, existência e existencial, manuelidade e decadência, ocupação e preocupação e muitas outras [...]" (p. 17).

Ora, quando formos ensinar o ser e o ente heideggerianos, previamente precisaremos definir tais conceitos que, em alguns aspectos, diferirão dos que Aristóteles, Avicena, etc., entenderam por o que seja o ser e o ente...

Vamos enveredar pela Metafísica de Avicena, que traduzirei do espanhol, e foi traduzido do árabe por Miguel Cruz Hernandez (Sobre Metafisica, Revista de Occidente, Madrid, 1950).

A filosofia árabe-muçulmana sofreu influências marcantes de Aristóteles, pois foi constantemente traduzido, imitado e comentado. Da mesma forma muitas doutrinas filosóficas tiveram influência platônica. Aristóteles, todavia, foi o grande filósofo que imperou na linha de pensamento que vem de Al-Kindī e Al-Fārābī e irá frutificar em Avicena. Gilson chamou a toda uma direção da escolástica medieval de agustinismo avicenizado; são Bonventura, Alexandre de Hales, Alberto Magno, São Tomás de Aquino, Duns Escoto, Rogério Bacon e muitos outros sofreram profunda influência de Avicena. São Tomás o cita mais de 250 vezes no correr de sua obra. Seu pensamento continuou em várias direções e alguns de seus princípios, como a teoria da intencionalidade, a distinção entre essência e existência, a doutrina dos universais, teoria do intelecto, prova da existência de Deus e tantas mais, fizeram-se pedras fundamentais dos grandes sistemas do século XIII.

Avicena parte de Al-Fārābī e das leituras, comentários da obra de Aristóteles, recebendo, igualmente, influências de Plotino. Era homem religioso que procurava buscar apoio racional para a sua fé. Seu pensamento irá evoluindo para elementos marcadamente neoplatônicos. Seguindo Aristóteles, dividia as ciências em teóricas e práticas. As teóricas subdividem-se em ciência suprema ou Metafísica, ciência 
média, a Matemática e ciência ínfima, a Física. A Metafísica é a ciência do ser, da substância e de Deus, e é a mais importante de todas as ciências.

O ser é o objeto primário e próprio da Metafísica. Todas as ciências - sustenta Avicena - se ocupam indiretamente do ser, mas só a Metafísica o tem como objeto particular. Começa estudando o uno e passa deste conceito à intuição do ser. Dentro já do ser, Avicena recorre à doutrina aristotélica da analogia. O ser - afirma com Aristóteles - aparece de muitas maneiras. De um lado, há o ser e suas representações; de outro, os graus do ser. São três os modos do ser: o das coisas reais, o da representação abstrata dessas coisas e do signo intencional. Nos graus do ser, frente ao ser per se e o ser in alio, coloca as negações e as privações. O ser per se é a substância; dentro desta, distingue as formas separada e material, e a matéria, que é a substância de ordem inferior.

Estudando depois as privações, chega Avicena à conclusão de que uma coisa pode existir legitimamente no espírito e faltar nos objetos exteriores; esta existência intitula-a de ser intencional. Os predicados, na realidade, só se lhes pode dar uma existência intencional. Disto parte Avicena para chegar à idéia do esse diminutum, cujo germe recolheu do livro V da Metafísica de Aristóteles, onde este cita o saber como exemplo. A idéia de intencionalidade, elaborada por Avicena e transmitida à Escolástica, teve larga permanência na História da Filosofia, chegando até Brentano, Husserl e Scheler. Na sua teoria do conhecimento a usa para explicar a relação entre os objetos e o sujeito. $O$ homem é um ser aberto às coisas; estas por si mesmas tendem também para o ser; um e outras possuem uma intencionalidade metafísica. Dentro do mecanismo do conhecer, desenvolve Avicena toda a sistemática das intenções, distinguindo entre intenções sensiveis, inteligiveis e non sensatas ou intermediárias; entre primeiras e segundas intenções e entre intenções formais e objetivas.

Para se entender a metafísica aviceniana não podemos omitir a sua teoria de intencionalidade e a distinção real entre a essência e a existência. Avicena começa por uma distinção conceitual; depois, aplica-lhe a teoria da intencionalidade e acaba realizando uma distinção real. A existência - diz - é extrínseca à essência e se agrega a esta. Continuando, estuda o problema da relação entre ambas, sem nunca sustentar - como o acusaram são Tomás e outros escolásticos - que a existência seria um acidente da essência. As essências, por si mesmas, não possuem existência, mas esta lhes é conferida pelo único Ser Necessário. Sem dúvida, as essências têm uma maior ou menor hierarquia metafísica, cuja ordem é esta: formas separadas, formas não separadas, substância separada, matéria e acidentes. A essência é aquilo que pode existir; a existência, aquilo pela qual existe e 0 ser concreto, o que existe. Continuando, Avicena estuda os elementos que entram na constituição das essências (gênero, espécie, matéria e forma), distinguindo entre o essencial constitutivo e seus concomitantes, para passar, em seguida, ao estudo dos universais.

O universal considerado em si mesmo só existe no espírito de um modo intencional; concretamente só existe realizado nas coisas. Avicena refuta a teoria platônica das idéias, ainda que, em valiosos manuais, se continue afirmando o contrário. Avicena é o primeiro que dá uma solução original conceitualista ao proble- 
ma dos universais, utilizando-se da sua dọtrina de intencionalidade, estudando o processo da abstração que, para ele, se apresenta em quatro graus: abstração sensivel, imaginativa, intelectual e estimativa. $\mathrm{O}$ ato da abstração se produz com uma múltipla colaboração entre as formas sensiveis, o intelecto humano e o intelecto agente. Este é como um sol que ilumina e faz inteligíveis em ato as formas e nosso entendimento. Neste processo há seis momentos: relações de caráter real entre o universal e as coisas concretas; presença da coisa real em si; iluminação do objeto e do entendimento pelo intelecto agente; abstração pelo intelecto em ato; relação mental que confere ao universal sua universalidade intencional e, por fim, a predicação do universal intencional de vários concretos individuais.

Avicena completa sua doutrina com o estudo dos graus metafísicos e dos predicáveis. Depois, fundamenta a acidentalidade na sua relação com a essência e não com a contingência, pois crê que a conexão do acidente com ela é intencional e não real.

A teoria da matéria em Avicena se afasta de Aristóteles e segue mais de perto Plotino, considerando-a como a mais inferior das substâncias, reduzindo o seu ser a pura receptividade. Considera a matéria como um mal, uma privação, uma deficiência do ser. É causa da multiplicidade e do mal: numa lista ontológica é o extremo da máxima deficiência; no alto da lista, estará Deus, Ato Puro, sem mancha alguma de matéria, que é a suprema perfeição. A matéria é a intermediária entre 0 ser e o puro não-ser. É simples possibilidade que necessita da colaboração da forma para atualizar-se. Tanto a matéria como a forma são substâncias em certo modo incompletas pois só se realizam propriamente até a formação do complexo comum. A matéria busca o ser, apresenta a intencionalidade de tender para ele. Avicena degrada a matéria, ressaltando a célebre imagem de que lembra a mulher desonrada e horrivelmente feia...

Entre a matéria e a forma há uma série de relações recíprocas que levam à atualização de uma e à individualização da outra. A forma, sem dúvida, tem uma primazia ontológica sobre a matéria por sua maior substancialidade; a união de ambas prepara o surgimento do corpo, ao qual se agrega a tridimensionalidade e constituindo o sujeito. A primazia é a forma corporeitatis, que colabora com a matéria signata quantitate determinata quando ocorre a individualização. Com estas idéias, Avicena deu origem às principais escolas medievais com o problema da individualização: à corrente que dá exclusividade à matéria signata e a que agrega ou sobreestima a forma corporeitatis.

Toda a filosofia de Avicena postula a existência de Deus. Ao excluir a contingência do seu sistema precisou de um Deus pelo qual todas as coisas sejam necessárias; ao sustentar a existência como extrínseca à essência, precisou de Deus para the conferir esse existir. Do mesmo modo, a distinção que faz entre a potência e o ato o conduz a um Ato Puro e à possibilidade de um Ser Necessário por si mesmo. $\mathrm{O}$ ato é mais importante do que a potência, porque é o bem e o ser. Por isto, o Ser Necessário é sempre Ser e Ato puros, sem mescla alguma de potência. O ser necessário se entende num sentido analógico e se divide no ser necessário por outros e no ser necessário per se. Este ser necessário per se é único e é o que confere a necessidade de ser aos demais seres que per se são possíveis e necessá- 
rios como causa de outros. A este Ser Necessário por si mesmo não podemos atribuir nenhum predicado; não é substância, nem pertence a gênero algum, pois é um gênero per se; carece de essência, pois esta é a sua própria existência.

Avicena vai enveredar pelo argumento ontológico partindo do conceito mesmo daquilo que seja o ser, sem necessidade da existência das criaturas, já que o Ser Necessário é aquele que seria contraditório considerar como não existente. Disto parte para assinalar a essência e os atributos de Deus. Deus é o Ser: sua essência é a sua existência. Não possui partes nem resultou de causa alguma. É Uno, Impenetrável, Autárquico (é o poder absoluto), a Verdade, a Inteligência, o Inteligente, o Inteligível, o Bem, o Belo, o Amante, o Amado, o Amor, é a Vida e nele não cabe nenhuma multiplicidade.

Ad extra se manifesta pela criação, a providência e a iluminação. A criação procede da Ciência Divina, que é onisciente e universal. Conhece todas as coisas de um só golpe e desde sempre através dos universais. A criação se produz ex necessitate naturae pois Avicena não separa a Vontade Divina de sua Ciência. A criação se faz ab aeterno, pois, se fosse temporal, antes da criação faltaria uma perfeição a Deus: a inerência do criado enquanto seja seu eleito. A criação é permanentemente conservada por Deus, porque o criador mais perfeito é aquele que conserva sempre a sua obra e Deus é o mais perfeito dos criadores. Esta criação e sua conservação recebem o fluxo da iluminação que Deus emana sobre todos os seres.

De Deus só pode proceder diretamente o primeiro ser criado, pois de outro modo entraria n'Ele a multiplicidade; os demais seres e a matéria procedem mediatamente de Deus. A criação emana da essência divina; mas, sem ser Avicena panteísta - embora a sua linguagem possa a esta conclusão nos levar - sustenta que a essência divina é irradiante e esta irradiação é o que ocasiona a criação. A mulitiplicidade da criação se produz pela composição da essência com a existência a partir do primeiro ser criado e chega até a matéria por meio do sistema das dez esferas. Cada uma delas possui a sua própria alma e sua própria inteligência. São as seguintes:

$1^{\mathrm{a}}$ - esfera das estrelas mais longinquas;

$2^{\text {a }}$ - esfera das estrelas fixas;

$3^{\mathrm{a}}$ - esfera de Satumo;

4 - esfera de Júpiter;

$5^{\mathrm{a}}$ - esfera de Marte;

$6^{\text {a }}$ - esfera do Sol;

$7^{\text {a }}$ - esfera de Vênus;

$8^{a}$ - esfera de Mercúnio;

$9^{\text {a }}$ - esfera da Lua;

$10^{\mathrm{a}}$ - o Mundo Sublunar.

Útima destas inteligências é o intelecto agente. $\mathrm{O}$ mundo sublunar sofre influências do celeste; neste habitam os seres imateriais, como os anjos e as formas separadas. Os anjos são concebidos como substâncias inteligentes, dotadas de ciência. O intelecto agente é estudado por Avicena como datur formarum. 
No estudo do mundo sublunar Avicena empresta especial relevo ao homem. Inicia este problema com as almas que considera o principio vital e a forma do corpo. Como principio vital considera dois tipos puros de alma: a alma vegetativa e a alma sensitiva. As almas incorpóreas apresentam-se com dois tipos: a alma angélica e a alma divina. A alma humana participa das características de ambos grupos. A alma é a perfeição do corpo e uma substância incorpórea e imortal.

Quanto ao intelecto, Avicena ressalta seus diversos significados. No sentido vulgar, denomina intelecto: à lucidez mental; aos conhecimentos universais adquiridos pela experiência; àquilo que se conhece como "inteligência". No sentido filosófico, designa: 0 intelecto distinto da ciência; o intelecto especulativo; o intelecto prático; o intelecto potencial ou material; o intelecto do hábito e as inteligências ativas. $O$ intelecto agente é o que atualiza os inteligiveis e passa 0 intelecto humano da potência ao ato. Avicena, poeticamente, explica a sua ação por meio de belíssimas imagens, culminando com a iluminação profética.

Vejamos um trecho de Avicena que nos fala sobre a profecia e o profeta:

\begin{abstract}
"É possível que uma pessoa tenha a alma tão fortificada por uma grande pureza e uma estreita união com os princípios intelectuais, até chegar ao extremo de inflamar-se só com um relâmpago da compreensão. Quero dizer: de receber a inspiração do Intelecto Agente em todas as coisas. Então, as formas que estão no Intelecto Agente se imprimem nela, imediatamente, de um só golpe e não se imprimem graças aos argumentos da autoridade, senão por uma disposição que inclui os termos médios. Pois nas coisas que você conhece somente por suas causas, as provas apoiadas na autoridade não são evidentes intelectualmente. Há, pois, neste caso, uma espécie de profecia, que é a mais alta das faculdades proféticas e a mais digna de ser chamada santa, constituindo o mais alto grau das faculdades humanas. Quem chega a este grau do conhecimento é chamado de profeta, e para ele confluem todas as formas materiais que rivalizam em perfeição [...]."

"O profeta não acontece a cada momento, já que a matéria apta para receber uma perfeição semelhante à sua se encontra em raros temperamentos. Diz-se que há uma missão a ser cumprida quando a revelaçăo precisa fazer alguma explicação que será útil para um bom governo do mundo ou modificações na ciência ou na politica. O enviado, então, dará a conhecer o que recebeu da emanação chamada revelação, que será útil para a retidão do mundo sensivel na política e do mundo intelectual na ciência."

"Por isso, é necessário que haja os profetas, homens com certas particularidades, que os outros homens não possuem, bem distintos do comum dos humanos. O profeta tem a faculdade de fazer milagres. Também consegue ouvir a palavra de Deus e ver os anjos sob uma forma visível. $O$ profeta pode ouvir Deus e os anjos. O que o profeta escuta não vem de palavras sonoras ou outros sons que procedem dos homens ou dos animais terrestres. Assim é aquele a quem é dada a revelação [...]" (p. 193-195 da tradução espanhola, Madrid, 1950, jả citada).
\end{abstract}

Metafísica - segundo Andrônico de Rodes, 50 anos a.C. - ou Ontologia - segundo Jacobus Thomasius, século XVII - requer do aluno de Filosofia muita atenção, memória e bom senso. Convém que saiba, de imediato, distinguir o que é Filosofia, problema filosófico, da pura ficção que nada acrescenta aos mesmos. Avicena, acima resumido, muito tem de ficcionista quando inventa a seqüência das esferas que pouco se baseou em investigações astronômicas e bastante apresenta de imaginação sem base numa pré-ciẹncia. São explicações imaginativas, criativo-literárias, que chegam ao belo mas que se distanciam das verdades mais verdadeiras. 
Cada pensador tem - como diríamos? - o seu próprio arquivo dos termos filosóficos, alguns por ele mesmo criados, podendo-se estabelecer o dicionário da filosofia de cada um deles. Decifrar cada filósofo seria um investigar do significado das palavras que emprega. Os analistas da linguagem, tão em moda, realçaramnos as investigações quanto ao que as palavras e as frases, e mesmo as circunstâncias e as entonações como são pronunciadas, conseguem transmitir alguma idéia filosófica. O perigo é a comunicação feita entre professores e alunos sem que o conteúdo das palavras que significam idéias, abstrações, essências fique em ambas as partes devidamente esclarecido, sem nenhuma dúvida. Porque, senão, o professor dirá uma palavra e cada aluno a terá com este ou aquele disparatado entendimento. $\mathrm{O}$ perfeito conhecimento filosófico não pode, humanamente, ser concluido em breves três anos, ou cinco. Requer muitas décadas de profundo e constante aprendizado e investigações. Para que dois ou mais pensadores se entendam é conveniente que, de saída, falem a mesma língua com a nítida definição de suas palavras, com aquilo que se entende pelos seus termos.

Para se entender e transmitir a obra de Heidegger precisa-se de, no mínimo, três anos letivos para uma clara exposição da mensagem do Ser e Tempo e o que escreveu o seu autor com seus complementos.

Às vezes, o entendimento de certas passagens nos vem como um insight instantâneo, uma intuição bergsoniana. Um pensador brasileiro hábil em instruirnos em questões de difícil compreensão é Monsenhor Urbano Zilles, da PUC do Rio Grande do Sul, membro da Academia Brasileira de Filosofia. Na sua Teoria do Conhecimento (Porto Alegre, EDIPUCRS, 1995), analisa o "conteúdo do pré-saber da pergunta" (p. 30). "Trata-se de mostrar o que devemos pré-saber simplesmente para fazer qualquer pergunta" (p. 30).

"De todas as coisas eu posso perguntar: o que 'é’? O que ‘é' isto? O que 'é' aquilo? Também posso perguntar tudo de uma só vez: o que 'é' isso tudo? o que é a totalidade e a unidade de tudo aquilo sobre que posso perguntar? De tudo o que é, nada pode fugir à possibilidade de ser perguntado se é, e o que é. E enquanto algo é perguntável justamente por seu 'é', é de todo perguntável, pois tudo o que esse algo é, entra em seu 'é'. E posso também perguntar para além de todos os limites, por tudo simplesmente, e sempre de novo esta pergunta será sobre o 'é' de tudo o que ultrapassa qualquer limite imaginável. Significa que tudo aquilo a que posso dirigir minha pergunta - e isso significa tudo o que é de uma ou outra forma - tem sua unidade fundamental no fato de que é; de cada coisa da realidade e da realidade total devo dizer que é perguntável pelo seu 'é'.

Ora, o que 'è', chamamos, com Martin Heidegger, de 'ente' [...]. Perguntável é tudo, e tudo é ente. Portanto, a pré-compreensão do meu pré-saber se dirige a todo ente simplesmente. Perguntar por todos os entes de uma vez, só posso se pergunto pelo ente enquanto ente. $\mathrm{E}$ perguntar o ente enquanto ente significa perguntar o ente por aquilo pelo que todos os entes formam uma unidade, por aquilo em que todos concordam simplesmente. Todos os entes são, ou seja, de cada um posso dizer que 'é'. Por isso, perguntar pelo ente enquanto ente significa perguntar por aquilo pelo qual o ente 'é'. Ora, o ente é ente pelo que 'é'. Assim, podemos finalmente dizer: ente é ente por virtude do ser. Perguntar pelo ente enquanto ente implica assim em perguntar pelo ser do ente, diferenciando-se do ente embora nele presente como seu fundamento.

Por isso Heidegger distingue ôntico e ontológico. O primeiro se refere ao ente e o último ao ser enquanto ser" (p. 34). 
"Ôntico - explica-nos Marilena Chauí no seu Convite à Filosofia (Ática, SP, 1994) - se refere à estrutura e à essência própria de um ente, aquilo que ele é em si mesmo, sua identidade, sua diferença em face de outros entes, suas relações com outros entes. Ontológico se refere ao estudo filosófico dos entes, à investigação dos conceitos que nos permitam conhecer e determinar pelo pensamento em que consistem as modalidades ônticas, quais os métodos adequados para o estudo de cada uma delas. Em resumo: ôntico diz respeito aos entes em sua existência própria; ontológico diz respeito aos entes tomados como objetos de conhecimento" (p. 238-239).

Os principais problemas filosóficos remontam às origens da Filosofia na Grécia Antiga. Aristóteles procurou conciliar Parmênides e Heráclito, ambos voltados para o problema do conhecimento, do confronto entre a realidade e suas representações. Heráclito revelava um certo pessimismo quando admitia que o objeto do conhecimento é um constante transformar-se, um fluir perene, pois quando se observa a realidade vemos que tudo evolui e que um ser que hoje engatinha, amanhã já anda e, logo depois, vira cadáver que se decompõe em ossos... Parmênides pretende reconstruir a validade do conhecer atribuindo ao Ser a imutabilidade, a imobilidade e a unidade, o que contraria frontalmente o depoimento dos sentidos. As duas vias, os dois caminhos, a da verdade e a da opinião, rejeitaram ao Ser 0 movimento, como sendo ilusório, irracional. "Os argumentos da Escola Eleata eram rigorosos. Diziam:

- admitamos que o Ser não seja uno, mas múltiplo. Nesse caso, cada ser é ele mesmo e não é os outros seres; portanto, cada ser é e não é ao mesmo tempo, o que é impensável ou absurdo. O Ser é uno e não pode ser múltiplo;

- admitamos que o Ser não seja eterno, mas teve um começo e terá um fim. Antes dele, o que havia? Outro Ser? Não, pois o Ser é uno. O Não-Ser? Não, pois o Não-Ser é o nada. Portanto, o Ser não pode ter tido um começo. Terá um fim? Se tiver, que virá depois dele? Outro Ser? Não, pois o Ser é uno. O Não-Ser? Não, pois o Não-Ser é o nada. Portanto, o Ser não pode acabar. Sem começo e sem fim, o Ser é eterno;

- admitamos que o Ser não seja imutável, mas mutável. No que o Ser mudaria? Noutro Ser? Não, pois o Ser é uno. No Não-Ser? Não, pois o Não-Ser é o nada. Portanto, se o Ser mudasse, tornar-se-ia Não-Ser e desapareceria. O Ser é imutável e o devir é uma ilusão dos nossos sentidos." (Marilena Chauí, Convite à Filosofia, p. 211, já citado).

José Ferrater Mora, no seu Diccionario de Filosofia Abreviado (Buenos Aires: Sudamericana, 1982), nos diz que "ser é um dos vocábulos mais difíceis de se entender por causa de suas diversas acepções e muitas interpretações que se vem dando a cada uma de suas significações. Às vezes, se entende o ser como a essência; às vezes, como a existência; às vezes, como o ente; às vezes como a substância. Não obstante, é óbvio que cada um desses citados conceitos tem definições que não coincidem sempre com as que se podem dar à noção de ser. Esta deveria ser distinta de qualquer outra. Muitos filósofos acreditam que o problema do ser não é somente autêntico, mas o problema fundamental da filosofia" (p. 377). 
O "ser enquanto ser" de Aristóteles significaria aquilo do ser evolutivo, que se transforma (Heráclito), que permanece no ser durante a sua evolução. Aquela criança, aquele homem adulto, aquele velho e aquele cadáver desse velho constituíram um só ser, que foi identificado como Pedro Paulo Antunes Figueira. O que permanece no evoluir do ser que é, e continua sendo. (Parmênides), é o ser perene, essencializado, cognoscivel na sua abstração. Não é o ser captado pelos sentidos, mas pela via da razão.

“A noção do ser foi expressada pelos pensadores gregos mediante a substantivação verbal de to ón. Ao tentar traduzi-la, os autores latinos clássicos notaram a dificuldade de traduzir um nome por meio de um verbo. Aristóteles destacava o ser do fato de que algo fosse. Isto introduziu no vocabulário medieval a diferença entre o ser e 0 ente; 0 primeiro foi considerado como aquilo que faz com que o segundo seja. Mas, como, às vezes, se entendia o ser como existência e, às vezes, com o sentido de essência, o anterior uso não suprimia todas as dificuldades.

Os gregos já aventavam o problema do é e a quem se deve atribuir este é. Pensavam que o ser é um atributo que pertence a tudo aquilo que é. Alguns entendiam que o ser do qual se falava era algo mais geral do que qualquer substância determinada, tão geral que, em rigor, nada seria possivel dela dizer além de que é.

Era o problema de Parmênides, que foi estudado por Platão a fundo, e por Aristóteles quando advertia que o fato de o ser seja geral não significa que seja o mais elevado de todos os gêneros. Aristóteles percebeu claramente que conceber o ser como a classe de todas as classes nos conduziria a contradições. Com a filosofia primeira Aristóteles inicia a discussão em torno do problema do ser. Sem dúvida, não o reșolveu, nem sequer proporcionou-lhe um marco definitivo. Isto porque o "ser como ser" aristotélico pode ser interpretado de duas maneiras. Na primeira, o ser é o ser mais comum de todos, válido para todos os entes e possuindo, por conseguinte, a extensão máxima. Na segunda, o ser é o ser superior a todos e princípio de todos. Os filósofos depois de Aristóteles (comentaristas antigos e pensadores escolásticos) debateram essas questōes inúmeras vezes: uns sustentaram que o problema do ser pertence à ontologia geral; outros, que é objeto da teologia. Uma das doutrinas que foi mais aceita, proposta por Avicena, foi defendida e precisada por são Tomás: o ser é o que se apreende de imediato. Não se pode confundir o ser, ou seja, o ente, com o ser transcendental, que existe em todos os seres e, por isso, está acima de todos. O ser não se reduz a um particular sensível nem ao universal meramente lógico, porque há várias interpretaçōes possiveis. A tomista se apoiava na concepção aristotélica segundo a qual o ser é tomado em diversas acepções, mas em cada uma das acepções haverá a relação a um princípio único. É a tese de que "o ser se diz de muitas maneiras", ou seja, a tese da analogia do ser. Segundo esta se pode dizer que são tanto as substâncias que existem, como o que não são substâncias, como os universais que, propriamente falando, não existem. Mas outros escolásticos sem deixar de serem aristotélicos defendiam a tese da univocidade do ser. Duns Escoto sustentou esta tese. Os termos univocos transcendentais, tais como ser que se aplica a uma classe de coisas ou às classes de todas as coisas. Duns declarou que o ser da essência dos seres singulares pode ser análogo, mas o ser da essência, como tal, é unívoco. A univocidade é, pois, um estado metafísico do ser" (no Dicionánio de Ferrater Mora).

O século XX - que, com os positivistas lógicos do Círculo de Viena, procuraram aclarar os intrincados conceitos filosóficos, a alguns denominando de pseudo problemas - viu, igualmente, enveredar-se o ser por caminhos ainda mais tortuosos com o Ser e o tempo de Heidegger. Quine, em Relatividade ontológica e outros ensaios (1969; já traduzido em Os Pensadores) comenta:

"Os filósofos com razão abandonaram a esperança de tudo traduzir para termos observacionais e lógico-matemáticos. Eles haviam perdido esta esperança mesmo quando ainda 
não haviam reconhecido, a título de razão para essa irredutibilidade, que grande parte dos enunciados não trazem seu lote privado de consequiências empíicas. E, para alguns filósofos, esta irredutibilidade aparecia como a bancarrota da epistemologia. Camap e outros posítivistas lógicos do Círculo de Viena já haviam dado ao termo metafísica, uma carga pejorativa, a de um termo que conota ausência de significado e o termo epistemologia era o próximo. Wittgenstein e seus seguidores, principalmente em Oxford, descobriram uma vocação filosófica residual na terapia: em curar filósofos da ilusão de que há problemas epistemológicos" (p. 170).

Heidegger, logo na Introdução de sua famosa obra, quer expor " a questão sobre o sentido do ser". E nos informa que "a questão referida não é, na verdade, uma questão qualquer. Foi ela que deu fôlego às pesquisas de Platão e Aristóteles para depois emudecer como questão temática de uma real investigação" (p. 27 da ed. brasileira).

Mais adiante acrescenta: "Repetir a questão do ser significa elaborar primeiro, de maneira suficiente, a colocação da questão" (p. 30). "Elaborar a questão do ser significa tornar transparente um ente" (p. 33). "O ser é sempre o ser de um ente" (p. 35).

$\mathrm{E}$, assim por diante, quanto mais Heidegger procura nos esclarecer, mais confunde os seus leitores, acrescentando conceitos de estrutura, de presença definindo " "a filosofia como sendo uma ontologia fenomenológica e universal que parte da hermenêutica da presença, a qual, enquanto analítica da existência, amarra o fio de todo questionamento filosófico no lugar de onde ele brota e para onde retorna" (p. 69 do Vol. I).

Acredito, sinceramente, que quando Quine procurou levar-nos ao conceito da existência, como, por exemplo, no seu From a Logical Point of View (N. York, 1963), principalmente no capítulo "On What There is" (tradução em Os Pensadores), o fez com muito propósito esclarecendo-nos diversas dúvidas. Esta seria uma tarefa do bom filósofo e nunca a de nos levar a caminhos obscuros e tortuosos para o esclarecido conhecimento...

Diante disto tudo - desses caminhos tão nebulosos à compreensão do Ser e seres, dos entes e do ser do ente e tanto mais... - quando escrevi minhas Obras Filosóficas, em quatro volumes, comecei em $O$ ser, o existir e 0 afirmar (v. 1, a partir da p. 161) a emparelhar a noção de ser com a de existir, logo depois, acrescentando-lhes o que se entende por afirmar, que é a parte que trata dos valores. Há muitas maneiras de existir e outras tantas de apreender mentalmente essas existências. A minha posição estrutural facilitou a simplificação daquilo que se pode entender por ser quando sinônimo de ente, de coisa, na sua generalidade de seres. Não voltarei a dizer o que já foi sobejamente dito no citado volume das minhas Obras Filosóficas. A originalidade está em incluir, no rosto dos seres, os seres de valor, típicos seres "de relação" entre o bem e a necessidade humana que dele necessita. Seres relacionais são, igualmente, existentes. Enquanto preocupavam-se tanto na definição dos termos, melhor seria que, através de análises realistas-problemáticas - análises que respeitam os limites cognoscitivos humanos fizessem classificações cada vez mais completas e perfeitas dos seres existentes ou possiveis. A Axiologia dá-nos, de imediato, a evolução dos seres inseridos no ainda tão pouco estudado grande Ser. O centro do Ser é o homem e sua consciên- 
cia. O ser como-é tende, forçosamente, para o ser-como-poderia ou como-deveriaser. A meta suprema do ser-consciente-humano é a afirmação onde existe o homem futuro na sua segurança máxima de existência. Se a existência é o fluir que nos leva ao nosso não-ser, no ser-que-se-será veremos a eliminação da nãoexistência. $\mathrm{O}$ homem do amanhã será aquele pleno de sua afirmação absoluta. Ao estudo do ser, certamente, para o complementar, devemos acrescentar o do valor. O ser medieval, aristotélico ficou frio e, apenas, racional. Heidegger já pretende situá-lo no mundo. Por fim, o ser-realista-axiológico será o completo, porque além de o situar diante da presença, ele a transcende às metas às quais se orienta. $\mathrm{E}$ esse orientar já se encontra na essência mítica do seu atingir ao futuro gloriosamente afirmativo.

A História da Metafísica, da Ontologia irá evoluindo do ser-coisa, do seressência, atemporal, para o ser-tempo, ser-humano-no-mundo, o ser-axiológicoinserido-no-mundo. O ser-axiológico é o voltado para o futuro onde se situa aquele como-poderia e o como-deveria-ser. É o ser invertido historicamente, isto é, o seu ser histórico não se volta para análises do seu passado, mas para o como-atingir o seu futuro de afirmação plena. Não conseguindo ser eterno na existência, pois essa se consțata na essência, procura a sua eternidade no como-poderá-ser e, por isso, valoriza a tecnologia e as ciências que lhe permitirão a permanência do seu ser-alma-e-corpo. À eternidade da alma, acrescentaremos a perenidade do corpo numa existência muito mais realista do que simplesmente problemática.

Como Deus é a sintese axiológica de todos os valores do homem, este luta para se transformar em Deus: quando não mais morrerá, terá a segurança máxima, o belo plenamente existencializado, 0 amor totalmente satisfeito, enfim, será o ser sem potencialidades de transformar-se no seu não-ser. O tempo é a espera do sercomo-é ao como-deverá-ser. As metas do homem, já contidas na idéia de Deus, revelam-nos que o ser-do-homem sem a sua consciência de valores nada é. Não haverá o Ser sem as consciências capazes de apreendê-lo. O existir é apenas o do homem, ser capaz dos valores. E estes valores orientarão os humanos para Deus, onde habita toda a plena Afirmação. 